\title{
OS DESDOBRAMENTOS ESTÉTICOS DO MEDO CÓSMICO: O RISO BAKHTINIANO, O HORROR LOVECRAFTIANO
}

João Pedro Bellas (UFF) Júlio França (UERJ)

Recebido em 10 mar 2017. João Pedro Bellas é mestrando de Teoria da Aprovado em 30 mar 2017.

Literatura e Literatura Brasileira, com a pesquisa "Fagundes Varela e o sublime romântico". Faz parte do grupo "Estudos do Gótico na Literatura Brasileira". Integrante dos Grupos de Pesquisa Estudos do Gótico (CNPq), coordenado pelo Júlio França e Luciana Colucci, e História e Ontologia da Ficção/Basanos (CNPq), coordenado por Fernando Muniz.

Júlio França tem doutorado em Literatura Comparada pela UFF (2006), com pós-doutorado pela Brown University (2015). É professor de Teoria da Literatura do Instituto de Letras e coordenador da área de Estudos de Literatura do Programa de Pós-graduação em Letras da UERJ. É líder do grupo de pesquisa Estudos do Gótico (CNPq) e integrante do GT da ANPOLL "Vertentes do Insólito Ficcional". Seus artigos mais recentes podem ser lidos na página "Sobre o Medo" (sobreomedo.wordpress.com).

Resumo: O artigo propõe a comparação entre as noções de "medo cósmico" formuladas por H. P. Lovecraft (2007) e Mikhail Bakhtin (2010), com especial atenção aos seus desdobramentos estéticos: 
no primeiro caso, o sublime de orientação burkeana observável na reflexão crítica e na ficção do escritor norte-americano; no segundo, a teoria do grotesco proposta pelo ensaísta russo a partir de seus estudos sobre a cultura popular medieval. O objetivo é demonstrar que embora o sublime e o grotesco sejam entendidos, por Lovecraft e Bakhtin, respectivamente, como consequências de um mesmo fenômeno antropológico - a percepção do papel insignificante do homem no cosmos - as duas categorias estéticas são empregadas para descrever obras artísticas que produzem efeitos de recepção tradicionalmente entendidos como antagônicos: o horror e o humor. A hipótese proposta para compreender tal paradoxo baseia-se no estudo de Noël Carroll (1999) sobre as relações de contiguidade entre o medo e o riso.

Palavras-chave: Ficção; Narrativa; Sublime; Grotesco; Terror.

Abstract: This paper proposes a comparison between the notions of "cosmic fear" formulated by H. P. Lovecraft (2007) and Mikhail Bakhtin (2010), with special attention to the different aesthetic consequences they cause: in the first case, the burkean sublime which is explicit in both the critical thinking and fiction of the American writer; in the second, the theory of the grotesque proposed by the Russian essayist from his studies about the folk culture in the Middle Ages. Our aim is to show that although Lovecraft's sublime and Bakhtin's grotesque are understood as consequences of the same anthropological phenomenon - the perception of man's insignificant role in the cosmos - both aesthetic categories are employed to describe works of art that give rise to effects traditionally taken as antagonistic: horror and humor. The hypothesis proposed to help understand this paradox is based on Noël Carroll's study (1999) about the relations of contiguity between fear and laughter.

Keywords: Fiction; Narratives; Sublime; Grotesque; Terror. 


\section{MEdo cósMico e SUBLIME}

O ensaio $O$ horror sobrenatural em literatura foi encomendado a H. P. Lovecraft por seu amigo W. Paul Cook, em 1924, que buscava uma história da ficção de horror sobrenatural para publicar em uma revista que pretendia editar. A primeira versão do texto foi finalizada somente em 1927 e publicada no primeiro e único volume do periódico The Recluse. A versão original sofreria diversas revisões até conhecer seu formato definitivo, publicado em 1939, postumamente.

Apesar de consistir fundamentalmente em uma breve história da literatura de horror, a obra tem início com dois capítulos nos quais são apresentadas algumas considerações teóricas em relação ao gênero. Isso se dá em função da preocupação de Lovecraft em não apenas apontar quais seriam os principais objetivos do ficcionista de horror - em última instância, produzir medo em seus leitores -, mas também em justificar esteticamente um gênero que nunca teve muito prestígio ao longo da história da literatura.

A defesa lovecraftiana da ficção de horror apoia-se fundamentalmente na formulação do conceito de medo cósmico em linhas gerais, o sentimento de terror que experimentaríamos quando confrontados por fenômenos que estivessem além de nossa capacidade de compreensão. Esse terror seria decorrente da percepção da insignificância do ser humano diante da grandiosidade e vastidão do universo.

A noção de medo cósmico é um reflexo das próprias posições filosóficas do escritor norte-americano. Em uma carta de 20 de julho de 1929 a R. Michael, Lovecraft apresenta a ideia de que 
talvez "o atual universo visível, nossa minúscula Terra e nossa raça de seres orgânicos inferiores formem apenas um incidente transitório e desprezível" (LOVECRAFT, 2012, p.138). Tal posição também é amplamente incorporada em sua ficção, como fica claro na já célebre abertura de "O chamado de Cthulhu" (1928):

A coisa mais misericordiosa do mundo é, segundo penso, a incapacidade da mente humana em correlacionar tudo o que sabe. Vivemos em uma plácida ilha de ignorância em meio a mares negros de infinitude, e não fomos feitos para ir longe. As ciências, cada uma empenhando-se em seus próprios desígnios, até agora nos prejudicaram pouco; mas um dia a compreensão ampla de todo esse conhecimento dissociado revelará terríveis panoramas da realidade e do pavoroso lugar que nela ocupamos, de modo que ou enlouqueceremos com a revelação ou então fugiremos dessa luz fatal em direção à paz e ao sossego de uma nova idade das trevas. (LOVECRAFT, 2012, p. 97)

Nas linhas que abrem $O$ horror sobrenatural em literatura, Lovecraft apresenta a tese que, a um só tempo, serve de base para sua concepção de medo cósmico e constitui o passo necessário para legitimar esteticamente o gênero do horror:

A emoção mais antiga e mais forte da humanidade é o medo, e o tipo de medo mais antigo e mais poderoso é o medo do desconhecido. Poucos psicólogos contestarão esses fatos, e sua reconhecida verdade deve estabelecer, para todos os tempos, a autenticidade e dignidade da ficção fantástica ${ }^{1}$ de horror como forma literária. (LOVECRAFT, 2007, p.13)

1 A tradução de weird fiction por "literatura fantástica" parece-nos inadequada, sobretudo em função da carga conceitual que o termo "fantástico" possui nos estudos literários. $\mathrm{O}$ que Lovecraft tem em mente é um tipo bastante específico de literatura sobrenatural, e não toda a literatura fantástica, lato sensu. 
Para Lovecraft, portanto, dois fatores garantiriam a legitimidade da literatura de horror, a saber, o caráter primitivo e fundamental do medo, e a intensidade dessa emoção. O autor defende categoricamente que até as mentes mais racionais possuiriam a predisposição requerida para serem afetadas por esse tipo de ficção. Aqui, o argumento lovecraftiano é de ordem biológica e psicológica:

Mas a sensibilidade está sempre em nós e, às vezes, um curioso rasgo de fantasia invade algum canto obscuro da mais dura das cabeças, de tal modo que soma nenhuma de racionalização, reforma ou análise freudiana pode anular por inteiro o frêmito do sussurro do canto da lareira ou do bosque deserto. Está presente nisso um padrão ou tradição psicológica tão real e tão profundamente enraizado na experiência mental quanto qualquer outro padrão ou tradição da humanidade; [...] uma parte integrada demais em nossa herança biológica mais profunda para perder sua contundência. (LOVECRAFT, 2007, p.14)

Tal herança psicológica poderia ser traçada até os antepassados mais primitivos do homem, que teriam respostas instintivas ao ambiente que os cercava, baseadas no prazer e na dor que as experiências proporcionavam. Aos eventos que escapavam à sua compreensão eram dadas interpretações maravilhosas, estando quase sempre presentes, nesse caso, sentimentos de medo e de terror. O funcionamento do universo, amplamente desconhecido - e, por isso, imprevisível -, tornou-se para nossos antepassados uma fonte tanto de bênçãos como, principalmente, das mais horríveis calamidades. 
Lovecraft sustenta que essa herança psicológica ancestral, que associa incerteza a perigo, combinada com a maior intensidade das experiências de dor em comparação com as de prazer, explicariam a existência e a efetividade da literatura de medo cósmico. A principal evidência de sua potência cultural seria o fato de que até mesmo autores que não se dedicavam exclusivamente ao horror produziram obras afinadas com o gênero - bons exemplos seriam "O papel de parede amarelo" (1892), de Charlotte Perkins Gilman; O rei de amarelo (1895), de Robert W. Chambers; $A$ outra volta do parafuso (1898), de Henry James; "A pata do macaco" (1902), de W. W. Jacobs; e O exorcista (1971), de William Peter Blatty.

Não se pode perder de vista que Lovecraft distingue dois tipos de histórias de horror, semelhantes em um nível superficial, mas bastante diferentes no que concerne ao domínio psicológico. De um lado, estaria a ficção de mero medo físico; do outro, a autêntica literatura de medo cósmico, privilegiada pelo autor:

A história fantástica ${ }^{2}$ genuína tem algo mais que um assassinato secreto, ossos ensanguentados, ou algum vulto coberto com um lençol arrastando correntes, conforme a regra. Uma certa atmosfera inexplicável e empolgante de pavor de forças externas desconhecidas precisa estar presente; e deve haver um indício, expresso com seriedade e dignidade condizentes com o tema, daquela mais terrível concepção do cérebro humano uma suspensão ou derrota maligna e particular daquelas leis fixas da Natureza que são nossa única salvaguarda contra os assaltos do caos e dos demônios dos espaços insondáveis. (LOVECRAFT, 2007, p.16-17)

2 Weird tale, conforme nota'. 
Lovecraft entende, portanto, que a ficção pautada no desconhecido é esteticamente superior à literatura de medo físico, justamente por ser mais capaz de suscitar no leitor o medo cósmico em seu sentido puro. $\mathrm{O}$ escritor norte-americano considera que o critério final para o julgamento da qualidade de uma obra de horror não seria o desenlace de seu enredo, mas sim a produção de uma determinada sensação - aquele profundo pavor capaz de despojar o indivíduo de sua capacidade de raciocinar e agir. Dessa forma, no modelo poético de Lovecraft, os aspectos puramente formais de uma narrativa são relegados a segundo plano ante a produção de um profundo sentimento de terror a partir do contato com o desconhecido. Portanto, o autor se insere em uma tradição crítica que remonta à Poética de Aristóteles - que pensa a obra de arte sob uma perspectiva que privilegia os efeitos que se almeja provocar no leitor (FRANÇA, 2010).

A literatura de medo cósmico legítima seria, portanto, aquela apta a produzir no leitor a emoção engendrada pelas forças desconhecidas do universo: um intenso horror capaz mesmo de solapar a razão. Na ficção lovecraftiana, isso se manifesta recorrentemente. Em “Dagon" (1919), um excelente exemplo dos efeitos do medo cósmico se encontra na cena em que o narrador avista a criatura que dá nome ao conto:

Então, de repente eu vi. Com um leve rumor que marcou sua chegada à superfície, a coisa apareceu acima das águas escuras. Vasto como um Polifemo, horrendo, aquilo dardejava como um pavoroso monstro saído de algum pesadelo em direção ao monólito, ao redor do qual agitava os braços escamosos ao mesmo tempo que inclinava a cabeça 
hedionda e emitia sons compassados. Acho que naquele instante que perdi a razão. (LOVECRAFT, 2012, p.25)

Ao se deparar com a criatura desconhecida, comparada ao Polifemo da Odisseia por sua vastidão e seu caráter monstruoso, o narrador se vê aterrorizado e despojado de sua capacidade de raciocinar. A descrição que compara o ser a "um pavoroso monstro saído de um pesadelo" é um indicativo de que se trata não apenas de algo que extrapola os limites da ciência moderna, mas que é também inapreensível à compreensão humana. O efeito último sobre o narrador é, como acontece em tantas outras narrativas lovecraftianas, a loucura.

Exemplos como o excerto de "Dagon" podem ser encontrados em diversas de suas obras. O propósito do presente artigo não é, entretanto, explorar a materialização da reflexão teórica de Lovecraft em sua ficção, mas apontar os desdobramentos estéticos de sua noção de medo cósmico. Nesse ponto, é possível notar uma clara aproximação com a estética do sublime desenvolvida a partir de meados do século XVIII, sobretudo com o modelo formulado pelo filósofo irlandês Edmund Burke.

É importante ressaltar que a ficção de horror moderna, de modo geral, é bastante tributária das ideias burkeanas. O tratado Uma investigação filosófica sobre a origem de nossas ideias do sublime e do belo (1757) é tradicionalmente considerado a fundamentação estética avant la lettre da literatura gótica, cujo marco inicial foi a publicação de $O$ castelo de Otranto (1764), de Horace Walpole. O que explica essa afinidade é o papel central que Burke confere ao terror em sua teoria do sublime. 
Ao promover o terror a um patamar mais elevado nas discussões sobre arte, Burke, na esteira da tradição filosófica do empirismo britânico, possibilitou a apreciação de imagens - como as montanhas e as construções góticas redescobertas durante o Renascimento - consideradas vulgares artisticamente ou até mesmo bárbaras aos olhos do Neoclassicismo, e conferiu legitimidade às poéticas pré-romântica e gótica, fundadas principalmente em excessos e transgressões.

No que concerne às ideias sobre as consequências estéticas do medo cósmico, a relação de Lovecraft com a teoria de Burke talvez seja ainda mais íntima. Na verdade, muitas das ideias do escritor norte-americano não são exatamente originais. A premissa de que a lembrança da dor e da ameaça de morte é mais intensa do que o prazer, bem como a defesa da incerteza - ou do desconhecido - como um componente essencial para a criação de uma atmosfera de medo cósmico, são todas ideias já presentes no livro do filósofo irlandês. Vale ressaltar que não há nenhum indício concreto de que Lovecraft tenha lido, ou sequer conhecido, a obra de Burke, de tal modo que não é possível falar exatamente de uma influência de um sobre o outro. O que é possível fazer, contudo, é traçar a relação entre os pensamentos de ambos os autores e demonstrar que é com um arcabouço teórico burkeano que o escritor de Providence encontrou uma maneira de legitimar filosoficamente a literatura de horror.

Em Burke, a tese de que as emoções que envolvem dor e perigo são mais intensas do que as sensações prazerosas está fundamentada na distinção entre prazeres e dores de natureza positiva e negativa. O filósofo rejeita a noção de que o prazer só 
existe através da cessação da dor - e vice-versa -, ao propor que o estado inicial do espírito não é nem o de prazer, nem o de dor, mas um estado neutro, de indiferença. Haveria, portanto, prazeres e dores puros, de natureza inteiramente positiva, isto é, que não teriam início mediante a interrupção um do outro.

Afirmar que há prazeres e dores positivos não exclui, contudo, a existência de prazeres e dores relativos. A sensação prazerosa que resulta da diminuição da dor não é, segundo Burke, suficientemente semelhante ao prazer simples e positivo para que seja considerada de mesma natureza. Ainda que os efeitos dessa sensação sejam benéficos, ela é bem diferente do prazer puro, que é simples e sem qualquer relação com a dor. Sendo assim, essa sensação, a qual o filósofo dá o nome de deleite, apesar de ser satisfatória, seria uma espécie de privação, pois sua existência é relativa e sempre está relacionada à dor (BURKE, 1993, p.45).

O segundo movimento de Burke para justificar a intensidade superior das ideias relacionadas à dor e ao perigo consiste em distinguir as ideias que seriam capazes de provocar uma forte impressão no espírito. Para o filósofo, elas poderiam ser subsumidas a dois grupos: o das ideias relacionadas à nossa vida em sociedade e o das relativas à nossa autopreservação. Interessa-nos aqui o segundo grupo, pois Burke faz valer um argumento fisiológico para defender a preponderância das paixões relacionadas aos nossos instintos de autopreservação: para que possamos desempenhar qualquer atividade, inclusive aquelas relativas à vida em sociedade, é necessário estarmos vivos e saudáveis. Logo, qualquer ameaça a nossas vidas seria capaz de causar uma forte impressão no espírito. 
Dada a intensidade das sensações relacionadas ao perigo, à dor e à morte, experimentá-las quando o indivíduo não estivesse realmente ameaçado, como ocorre nas artes miméticas, consistiria na matriz ideal para as experiências estéticas mais potentes. Para Burke, esse seria exatamente o domínio do sublime:

Tudo que seja de algum modo capaz de incitar as ideias de dor e de perigo, isto é, tudo que seja de alguma maneira terrível ou relacionado a objetos terríveis ou atua de um modo análogo ao terror, constitui uma fonte do sublime, isto é, produz a mais forte emoção de que o espírito é capaz. (BURKE, 1993, p.48)

Assim, no modelo burkeano, enquanto a ideia de beleza estaria ligada a características sociais positivas, que gerariam amor e prazer, o sublime estaria relacionado à autopreservação e, consequentemente, ao deleite - o prazer negativo gerado pela cessação de uma dor.

Segundo a formulação burkeana, o sublime afetaria o espírito em quatro graus: três inferiores, a saber, admiração, reverência e respeito; e o efeito mais intenso, o assombro. Esse seria precisamente o efeito acarretado pelo medo cósmico, uma vez que, quando experimenta esse tipo de pavor, o indivíduo torna-se incapaz de agir e de pensar. Da mesma forma, Burke (1993, p.65) afirma que, quando está em um estado de assombro, "o espírito sente-se tão pleno de seu objeto que não pode admitir nenhum outro nem, consequentemente, raciocinar sobre aquele objeto que é alvo de sua atenção".

Ideias capazes de provocar a paixão do assombro, e, consequentemente, proporcionar o deleite são fontes em 
potencial do sublime - é o caso, por exemplo, das ideias relacionadas ao poder, à infinitude e à vastidão, todas, segundo Burke, aptas a instilar terror. Uma condição comum e fundamental às ideias terríveis é a obscuridade:

Para tornar algo extremamente terrível, a obscuridade parece ser, em geral, necessária. Quando temos conhecimento de toda a extensão de um perigo, quando conseguimos que nossos olhos a ele se acostumem, boa parte da apreensão desaparece. Qualquer pessoa poderá perceber isso, se refletir o quão intensamente a noite contribui para o nosso temor em todos os casos de perigo e o quanto as crenças em fantasmas e duendes, dos quais ninguém pode formar ideias precisas, afetam os espíritos que dão crédito aos contos populares sobre tais espécies de seres. (BURKE, 1993, p.66-67)

A obscuridade, contudo, refere-se não apenas a situações de ausência de luz, mas também se aplica a objetos sobre os quais não se pode formar ideias claras, ou mesmo àqueles que são completamente ininteligíveis. Burke entende que a condição da obscuridade é um componente essencial para tornar qualquer objeto terrível, sendo, por esse motivo, um elemento vital para a produção do sentimento do sublime.

A condição de ser obscuro, no modelo burkeano, assemelha-se muito à ser desconhecido na proposição lovecraftiana. Ainda que não se refira explicitamente a Burke, o escritor norte-americano não somente assimila o ponto de vista do filósofo irlandês, como vai além, defendendo que a própria obscuridade - entendida como um correlato da noção de desconhecido - é algo a ser temido. Esse 
é, de fato, o principal pressuposto da asserção lovecraftiana de que o tipo mais intenso de medo é o medo do desconhecido - uma premissa, portanto, burkeana.

Tendo por base outra premissa burkeana, o ficcionista norteamericano foi capaz de conferir legitimidade à narrativa de horror. O autor, assim como Burke, entende que a dor e o risco de morte são sensações mais vívidas e potentes, e, assim, mesmo sem usar o termo deleite, supõe que os prazeres negativos são mais intensos do que os positivos. Esse era o motivo pelo qual as histórias de horror despertariam na humanidade um enorme fascínio, e mesmo que elas enfrentassem forte oposição por parte da tradição crítica, sobreviviam e se desenvolviam continuamente (LOVECRAFT, 2007, p.13).

Um hipotético modelo burkeano-lovecraftiano de legitimação estética do gênero de horror poderia ainda se valer da importância fisiológica da experiência do sublime terrível - explícita em Burke, mas in absentia em Lovecraft. Tal proposição, que parece aludir ao caráter terapêutico que Aristóteles identificava na catarse trágica, defende a utilidade de se submeter a experiências de horror, baseada na tese de que nosso sistema emocional precisaria ser exercitado tanto quanto o nosso corpo (BURKE, 1993, p.140141). Nesses termos, julgamos lícito especular que, no sublime burkeano de Lovecraft, a experiência do horror ficcional seria um modo de lidar com o medo cósmico, pois as narrativas do gênero possuiriam um efeito catártico na medida em que permitem experimentar, no plano mimético, sensações relacionadas à dor, à morte e ao terror. 


\section{MEDO CÓSMICO E GROTESCO}

O modelo descritivo do grotesco proposto por Mikhail Bakhtin é um dos mais influentes e disseminados no campo dos estudos literários. Seu entendimento da categoria estética privilegia, abertamente, sua expressão na cultura popular medieval, até mesmo porque suas reflexões sobre o tema surgem no escopo de seu estudo sobre a obra de François Rabelais. Sua apreciação das transformações profundas dos sentidos do efeito grotesco na arte moderna é precisa, ainda que seja muitas vezes comprometida por um pouco fundamentado juízo de valor ${ }^{3}$ quanto à inferioridade do grotesco romântico em comparação com sua contraparte medieval. Notável também é sua proposição de que a arte grotesca seria consequência de uma condição humana atávica: o "medo cósmico", assim definido por ele:

Medo de tudo que é incomensuravelmente grande e forte: firmamento, massas montanhosas, mar-e o medo das perturbações cósmicas e das calamidades naturais, nas mais antigas mitologias, concepções e sistemas de imagens, e até nas próprias línguas e nas formas de pensamento que elas determinam. Uma certa lembrança obscura das perturbações cósmicas passadas, um certo temor indefinível dos abalos cósmicos futuros dissimulam-se no próprio fundamento do pensamento e da imagem humanos. (BAKHTIN, 2010, p.293)

É bastante explícita a semelhança entre a noção bakhtiniana de medo cósmico e a de Lovecraft. Eles discordam, porém, quanto ao papel que coube aos sistemas religiosos na assimilação

3 Bakhtin defende que a profundidade, a plurissignificação e força dos temas grotescos só são possíveis através da visão carnavalesca do mundo observável na cultura popular. Fora daí, os temas grotescos tornar-se-iam unilaterais, débeis e anódinos. 
desse temor avassalador. O americano entendia que as religiões organizadas incorporaram os aspectos benéficos do imaginário sobre o desconhecido, cabendo à cultura popular oral os aspectos nefastos, que teriam se materializado na tradição das narrativas de horror sobrenatural. Já o russo defendia um modelo inverso, em que o "temor inspirado pelas coisas materiais de grande porte e pela força material invencível" fora "utilizado por todos os sistemas religiosos com o fim de oprimir o homem, de dominar a sua consciência" (BAKHTIN, 2010, p.293-4), cabendo à cultura popular o enfrentamento do temor cósmico por meio do humor:

Esse medo cósmico foi legado pela impotência dos primeiros homens diante das forças da natureza. A cultura popular ignorava esse temor, aniquilava-o por meio do riso, da corporificação cômica da natureza e do cosmos, pois ela estava fortalecida na base pela confiança indefectível no poder e na vitória final do homem. Pelo contrário, as culturas oficiais utilizavam muitas vezes, e até mesmo cultivavam, esse temor a fim de humilhar e oprimir o homem. (BAKHTIN, 2010, p.294. Nota 8)

Bakhtin propunha que a forma concreta de enfrentamento do medo cósmico na cultura popular medieval baseava-se não em esperanças transcendentes da eternidade do espírito, mas em uma visão materialista do mundo, em que os elementos cósmicos eram experimentados no corpo do próprio homem:

Assim, a matéria fecal e a urina, matéria cômica, corporal, compreensível, tinha aí um papel muito importante. Elas figuram também em quantidade astronômica, numa escala cósmica. O cataclismo cósmico, descrito com a ajuda das imagens do baixo material e corporal, é rebaixado, humanizado e 
transformado num alegre espantalho. Assim o riso venceu o terror cósmico. (BAKHTIN, 2010, p.294-5)

Bakhtin observa, em autores como Boccaccio, Shakespeare, Cervantes e Rabelais, a predominância do que chamará de princípio da vida material e corporal, referindo-se às imagens hipertrofiadas do corpo, da bebida, da comida, da satisfação de necessidades naturais e da vida sexual. Ele entende que tais imagens - às quais a tradição crítica se refere com termos como "fisiologismo grosseiro", "biologismo" e, mais comumente, "naturalismo" - são herança da cultura cômica popular medieval, caracterizada por "uma concepção estética da vida prática" à que dará o nome de realismo grotesco (BAKHTIN, 2010, p.16-17).

Um traço marcante do realismo grotesco seria a transferência, ao plano material e corporal, de tudo o que é espiritual e idealizado. Bakhtin tem em mente as paródias medievais de textos sagrados, nas quais o humor teria justamente a função de materializar os temas elevados e abstratos. Rebaixamento e degradação seriam atitudes fundamentais do realismo grotesco:

Degradar significa entrar em comunhão com a vida da parte inferior do corpo, a do ventre e dos órgãos genitais, e portanto com atos como o coito, a concepção, a gravidez, o parto, a absorção de alimentos e a satisfação das necessidades naturais. (BAKHTIN, 2010, p.19)

Para Bakhtin, contudo, as degradações do realismo grotesco na cultura cômica popular da Idade Média precisam ser compreendidas em seu valor ambivalente. Não são apenas destrutivas, uma vez que atendem também a um ímpeto positivo, regenerador, e davam lugar a um sempre consequente renascimento. Essa compreensão 
do caráter cíclico primordial da vida, própria do realismo grotesco medieval, foi gradativamente desaparecendo na modernidade:

Já não é o inferior positivo, capaz de engendrar a vida e renovar, mas um obstáculo estúpido e moribundo que se levanta contra as aspirações do ideal. Na vida cotidiana dos indivíduos isolados as imagens do "inferior" corporal conservam apenas seu valor negativo, e perdem quase totalmente sua força positiva; sua relação com a terra e o cosmos rompe-se e as imagens do "inferior" corporal ficam reduzidas às imagens naturalistas do erotismo banal. (BAKHTIN, 2010, p.20)

Ainda que a paródia tenha sobrevivido à modernidade, Bakhtin entende que seu caráter literário e formal pouco contém de sua predecessora medieval. Se a paródia moderna conserva o impulso de degradar e rebaixar, ela o faz de modo exclusivamente negativo, desprovido de ambivalência regeneradora.

A degeneração do grotesco, isto é, a perda de seu potencial revigorador seria um dos sintomas do afastamento da literatura moderna de suas raízes orais e populares e da consequente consolidação em mera tradição literária. Elementos do grotesco revivificante subsistiriam apenas de modo esparso, em gêneros como a commedia dell'arte, em obras como a de Molière e Jonathan Swift, e nos romances filosóficos de Voltaire e Diderot. Bakhtin acredita também que a literatura realista dos séculos XVIII, XIX e XX seja amplamente tributária do realismo grotesco da cultura popular renascentista, o que poderia ser observado na exploração de imagens grotescas nas obras de Balzac, Hugo, Dickens, entre outros. Desprovidas, porém, de seu lado positivo, esses "destroços do realismo grotesco" (BAKHTIN, 2010, p.21) teriam conduzido 
progressivamente ao abastardamento do realismo grotesco, que se degenerou na forma de empirismo naturalista. No Naturalismo, as imagens da vida material e corporal (beber, comer, satisfazer necessidades naturais, copular, parir), por serem índices inequívocos do substrato animal do ser humano, perdem sua significação regeneradora e são compreendidos como marcas de modos inferiores de existência.

Bakhtin não afirma que o grotesco desapareceu na era romântica, mas que ressurgiu, dotado de um novo sentido, apto "para expressar uma visão do mundo subjetiva e individual, muito distante da visão popular e carnavalesca dos séculos precedentes" (BAKHTIN, 2010, p.32). Uma das transformações operadas pelo individualismo moderno pode ser observada nas relações entre a arte grotesca e o cômico. O riso não teria desaparecido, mas deixado de ser jocoso e alegre para tomar a forma de ironia ou sarcasmo, perdendo, assim, seu aspecto regenerador e positivo torna-se um "grotesco de câmara" (BAKHTIN, 2010, p.33). Contudo, é em relação ao polo oposto, ao do terrível, que encontraríamos a principal característica a distinguir o grotesco moderno do medieval, dando forma ao que Bakhtin (2010, p.32) irá denominar, sem maiores detalhamentos, de "romance grotesco ou negro"4.

Essa forma negativa assumida pelo grotesco no Romantismo explicar-se-ia pela reação de horror que tantos artistas românticos experimentaram ante as transformações do mundo moderno:

A euforia produzida pelas conquistas da ciência e do progresso tecnológico tinha dado ao homem a falsa expectativa de um futuro livre de dores e misérias. 4 Bakhtin não esclarece o termo, mas supomos ser razoável especular que se trate de uma referência ao romance gótico. 
Esse projeto foi, contudo, sendo frustrado ao longo do grande século XIX. No plano político, o fracasso da Revolução Francesa em realizar os anseios iluministas de progresso e igualdade redundou no reinado do Terror. No plano científico, as noções de homem e de natureza foram violentamente abaladas pela secularização do conhecimento e da vida, tendo por consequência a consolidação da ideia de que o ser humano estava muito mais próximo do reino animal do que da posição privilegiada - e divinizada - que a tradição judaicocristã propunha. No plano social, a crescente urbanização do Ocidente deu forma às cidades modernas, ajuntamentos humanos como jamais vistos na história do homem: superpopulosas, insalubres, sombrias, labirínticas, violentas e corruptas. No plano tecnológico, a industrialização, por um lado, criava condições sub-humanas de emprego e, por outro, mecanizava as guerras, anunciando o que seria confirmado ao longo do século subsequente - a utilização do conhecimento para a produção de armas de destruição em massa. (FRANÇA, 2017, p.227)

Bakhtin entende que o grotesco teria sido, portanto, o modo artístico adequado para que os escritores da era moderna pudessem dar forma ficcional a uma visão de mundo negativa, segundo a qual o universo seria algo "terrível e alheio ao homem" (BAKHTIN, 2010, p.34). Para nossos fins neste artigo, postulamos que a ascensão do grotesco terrivel é, em grande parte, consequência de uma crise produzida pela razão: quanto mais o homem se afastava de uma cosmovisão religiosa e buscava entender o mundo por uma perspectiva científica, mais se confrontava com a nada idílica condição humana. A era moderna exigia um tipo de arte capaz de expressar a angústia provocada pelo esforço racional de entender o mundo. 
As "imagens do grotesco romântico", diz Bakhtin (2010, p.34), "são geralmente a expressão do temor que inspira o mundo e procuram comunicar esse temor aos leitores". Tal transformação na função estética do grotesco poderia ser facilmente observada em características recorrentes das obras do Realismo-Naturalismo oitocentista: as necessidades naturais - beber, comer, copular, parir etc., ou, como Bakhtin as denomina, a "vida material e corporal" - convertem-se em índices de vidas inferiores, por tornar óbvia a semelhança entre o ser humano e os demais animais; a loucura deixa de ser saudada por seu potencial de oferecer um olhar diferenciado em relação ao senso comum, e passa a encarnar a tragédia do isolamento do indivíduo nas sociedades modernas; o diabo, por sua vez, não é mais o "espantalho alegre" da cultura medieval, mas a figuração sombria do desespero do homem moderno ante um mundo cada vez mais hostil, em acelerado processo de transformação, rumo a um futuro, mais do que nunca, desconhecido: "no grotesco romântico, o diabo encarna o espanto, a melancolia, a tragédia. O riso infernal torna-se sombrio e maligno" (BAKHTIN, 2010, p.36).

Em Bakhtin, portanto, a essência do grotesco - seja em seu ápice, quando a condição humana do medo cósmico é superada pelo riso; seja em sua decadência moderna, quando a atualização do medo cósmico, a visão desencantada de mundo, redunda em ironia e sarcasmo - está indissociavelmente relacionada tanto a horror quanto a humor. 


\section{HORROR VERSUS HUMOR}

Não obstante apresentem definições semelhantes para a noção de medo cósmico, Lovecraft e Bakhtin parecem divergir em relação às consequências desse sentimento. Se, por um lado, o escritor norte-americano advoga um efeito similar ao assombro que, de acordo com o modelo estético de Edmund Burke, acompanharia a experiência do sublime, por outro, o teórico russo privilegia uma expressão do grotesco segundo a qual o medo cósmico seria vencido pelo riso revivificante. Em suma, embora tomem como ponto de partida o mesmo fenômeno - a percepção da insignificância humana no universo -, Lovecraft e Bakhtin desenvolvem modelos teóricos que conduzem a desdobramentos estéticos que seriam, ao menos à primeira vista, paradoxais: o horror e o humor.

Noël Carroll, no artigo intitulado "Horror and humor" (1999), propõe-se a investigar precisamente as relações entre essas duas emoções, aparentemente antagônicas. Seu ponto de partida é a intrigante possibilidade de uma mesma figura poder ser utilizada, em determinadas situações, para provocar pavor, e, em outras, para proporcionar o riso ${ }^{6}$.

Ele enumera alguns exemplos ficcionais que indicariam a existência de uma correlação entre as estruturas dos gêneros relacionados ao horror e os relacionados à comédia - entre eles, destaque-se, a obra fundadora do Gótico, O castelo de Otranto,

6 Um exemplo contemporâneo desse fenômeno seria a figura ficcional do zumbi: utilizado recorrentemente em obras de horror ao menos desde The Night of the Living Dead (1968), de George Romero, tem sido empregado a serviço da comédia em filmes como Shaun of the Dead (2004), de Edgar Write; Fido (2006), de Andrew Curie; Zombieland (2010), de Ruben Fleischer; Warm bodies (2013), de Jonathan Levine; e na série televisiva norte-americana iZombie (2015-2016), desenvolvida por Rob Thomas e Diane Ruggiero-Wright. 
com sua indefectível mistura de bufonaria e solenidade, admitida pelo próprio Horace Walpole (1996, p.22). Faz referência também a autores que já mencionaram semelhanças entre humor e horror - Edgar Allan Poe, Sigmund Freud, Robert Bloch, entre outros. No entanto, apesar dos inúmeros exemplos, Carroll reforça que por mais que se possa demonstrar a afinidade empírica entre esses dois estados mentais, sua proximidade é contraintuitiva. Por esse motivo, o filósofo procura esboçar duas teorias, uma para o gênero de horror, outra para o de humor, com o objetivo de isolar as semelhanças e as diferenças entre ambos.

A teoria do gênero de horror proposta por Carroll no artigo é a mesma que defendeu em sua obra seminal de 1990, A filosofia do horror ou paradoxos do coração. Nela, ao distinguir entre as diversas emoções próximas do medo, ele postulava que a presença de um monstro seria o elemento determinante das narrativas de horror, aquilo que as distingue por excelência. "Monstro", para o filósofo, é qualquer ser extraordinário em um mundo ordinário.

A presença de monstros, contudo, não seria condição suficiente para a produção do horror artístico, uma vez que eles podem aparecer em narrativas as quais não somos propensos a identificar como pertencentes ao gênero - pensemos em personagens como Chewbacca, de Star Wars, por exemplo. Para Carroll, é a atitude das demais personagens diante do monstro, ou seja, a percepção intradiegética da letalidade e do caráter sobrenatural da monstruosidade, que determinaria a peculiaridade desse protagonista das obras de horror. O monstro de horror precisa representar, no mundo diegético que habita, uma ameaça física e uma perturbação da ordem natural. 
O traço distintivo do gênero de horror seria, portanto, o estado emocional peculiar que os monstros são capazes de suscitar. Vale dizer que emoções devem ser entendidas como estados mentais, na medida em que são dirigidas a algo, e que não são opostas à cognição. Ao contrário, um sentimento é guiado por um critério formal: para que uma determinada personagem seja considerada horrífica, ela deve ser objeto de um juízo que lhe confira letalidade.

No modelo de Carroll, além de sua letalidade, o monstro horrífico também precisaria ser, necessariamente, repulsivo. Para fundamentar tal ponto, o filósofo recorre à noção de impureza desenvolvida por Mary Douglas (1991). Em Pureza e perigo, a antropóloga postulou que seres ou coisas intersticiais, isto é, que não podem ser arroladas a uma única categoria conceitual de uma cultura, costumam ser tomadas como impuras. A atribuição de impureza à monstruosidade estaria relacionada, portanto, à percepção de que o ser monstruoso transgride ou viola esquemas de categorização cultural. Nesses termos, o monstro é impuro por ser uma criatura intersticial, uma contradição categórica (CARROLL, 1999, p.152).

A relevância da noção de impureza para uma teoria do horror seria corroborada pelos próprios exemplos ficcionais, uma vez que a maioria expressiva das criaturas que compõem o bestiário do cânone do horror podem ser descritas como seres intersticiais: o lobisomem está situado no continuum entre o homem e o animal, Drácula está vivo e morto ao mesmo tempo, e Frankenstein é um ser natural e artificial concomitantemente, e assim por diante. 
Além de constituir um dos pilares de seu modelo descritivo do horror artístico, a noção de impureza é um ponto essencial na argumentação de Carroll, pois permite estabelecer a ponte entre esse gênero e o humor, já que a comédia - ou ao menos um tipo específico de humor - também operaria por meio de violações de categorias (CARROLL, 1999, p.152). Carroll tem em mente, como modelo descritivo da estrutura do cômico, a teoria da incongruência.

Essa teoria teria florescido no século XVIII, como reação à teoria da superioridade, associada a Thomas Hobbes ${ }^{7}$. Em resposta à tese hobbesiana, Francis Hutcheson sustentava que a base do divertimento cômico é o contraste entre ideias e/ou conceitos:

[...] geralmente, a causa do riso é a reunião de imagens que possuem ideias contrárias, bem como certa semelhança com a ideia principal: esse contraste entre ideias de grandeza, dignidade, santidade, perfeição e ideias de maldade, inferioridade e profanação parece ser o espírito do burlesco, e grande parte de nossos gracejos e piadas é fundada nele. (HUTCHESON, Apud CARROLL, 1999, p.153 - tradução nossa)

A principal base da teoria da incongruência é, portanto, a noção de que um componente essencial do humor é a justaposição de categorias contrastantes. Apesar de parecer vaga, essa tese foi retomada posteriormente por pensadores como Kant e Bergson. Um dos mais notáveis desenvolvimentos da teoria foi feito por Schopenhauer, que sustentava que o pré-requisito do humor seria a falha na tentativa de subsumir um particular a um conceito. Em

7 De acordo com a noção hobbesiana, o riso teria sua origem na percepção de que o objeto cômico é inferior. Um contraexemplo óbvio estaria no fato de que muitas vezes rimos de piadas das quais nós mesmos somos o alvo. Por esse motivo, o critério de superioridade se mostraria inadequado para dar conta de uma teoria ampla do humor. 
outras palavras, semelhante à noção de impureza que sustenta a hipótese do caráter cognitivo do horror, apresentada acima, a justaposição cômica também poderia ser entendida em termos de um erro de categorização.

A teoria da incongruência torna possível comparar, estruturalmente, horror e humor, na medida em que ambos os gêneros obteriam seus efeitos estéticos correspondentes a partir de estratégias discursivas que operam transgressões de categorias cognitivas. Vale dizer que Carroll (1999, p.155) está ciente de que a teoria da incongruência talvez seja insuficiente para dar conta de maneira completa da comédia. Entretanto, ela constitui uma ferramenta bastante útil para ao menos identificar uma subclasse do humor, e, consequentemente, ajudaria a entender o porquê de tantas imagens horríficas poderem também ser utilizadas para proporcionar o riso:

O movimento do horror para o humor ou viceversa que nos parece tão contraintuitivo, então, pode ser explicado em termos daquilo que o horror e ao menos um tipo de humor [...] compartilham. Pois a intersticialidade e transgressão categórica que serve como uma das condições necessárias mais essenciais para o estado mental do horror desempenha um papel como parte de uma condição suficiente para alcançar o estado mental do divertimento cômico. (CARROLL, 1999, p.156 tradução nossa)

Gostaríamos de desdobrar as consequências da conclusão de Carroll, utilizando-nos da mesma fundamentação teórica por ele empregada em A filosofia do horror. Se, como vimos acima, o que caracteriza o monstro de horror é sua letalidade e repulsividade, 
e os elementos repulsivos não são estranhos ao cômico, o que possibilitaria a transformação do monstro horrífico em um objeto de humor seria a eliminação de seu caráter letal. Ora, a letalidade da criatura monstruosa, nas narrativas ficcionais, não é um dado factual para o leitor, pois tanto os seres capazes de horrorizá-lo quanto àqueles com quem estabelece vínculos empáticos, não são seres reais, mas personagens ficcionais. A letalidade capaz de horrorizar o leitor, portanto, é percebida por meio de uma operação mental, algo que Carroll (1999, p.137-138) chama de assimilação.

Carroll propõe o uso do termo assimilação no lugar de identificação para eliminar a enganosa sugestão de emoções idênticas contida no segundo termo. Ele rechaça a tese de haver uma identificação emocional plena dos espectadores com os personagens ficcionais. Para ele, o que ocorre é um processo cognitivo em que o espectador "avalia" a compreensão que a personagem tem da situação em que se encontra. Não se trata, portanto, de replicar o estado mental da protagonista: o espectador percebe aspectos da situação que não são enfocados pela protagonista, e reage de forma muito diversa - basta lembrar que ele está experimentando prazer com a cena, a protagonista não.

Carroll é um defensor da Teoria do Pensamento, um modelo de compreensão da ficção que postula que, nas narrativas de horror, não nos horrorizamos por estarmos iludidos quanto a existência de vampiros e que seremos a próxima vítima de Drácula, mas pelo trabalho mental de imaginarmos a existência de um ser como Drácula. Horrorizar-se seria, portanto, um processo cognitivo, e não meramente uma reação emocional. 
O medo ou o riso seriam consequências do sucesso ou do fracasso da obra de horror em promover a ameaça e a letalidade da transgressão categórica, isto é, da monstruosidade apresentada. De modo inverso, riso ou medo seriam consequências do sucesso ou do fracasso da obra de humor em não permitir que a transgressão categórica apresentada seja moralmente repulsiva ou assustadora.

Valendo-se de tal hipótese, poderíamos especular que o sublime lovecraftiano se daria quando a obra de horror é bem sucedida e a situação de risco dos protagonistas é assimilada pelo leitor. Por sua vez, o grotesco bakhtiniano seria resultado da obra de humor que não fosse bem sucedida em subtrair os elementos atemorizantes das transgressões categóricas apresentadas.

\section{UM FALSO PARADOXO, PORTANTO}

A partir das considerações de Noël Carroll, e dos desdobramentos que propomos, é possível começar a compreender por que Lovecraft e Bakhtin, embora partindo do mesmo ponto - a percepção da insignificância humana no cosmos -, estabelecem modelos estéticos que privilegiam diferentes efeitos de recepção. O que, à primeira vista, parece um paradoxo, é, na verdade, consequência da semelhança entre os procedimentos empregados para produzir dois estados mentais distintos. Apesar de serem diferentes no que diz respeito ao grau de periculosidade dos objetos aos quais são dirigidos, tanto o horror quanto o riso requerem uma transgressão de categorias.

O movimento do horror para o humor e vice-versa não é tão contraintuitivo quanto parece. Ao contrário, ele é, de algum modo, natural e não deveria ser inesperado. Curiosamente, algumas 
narrativas exploram justamente essa contiguidade. Além do supracitado Horace Walpole, outro autor que aborda essa questão é E. T. A. Hoffmann. O célebre "O homem da areia" (1816) aponta para essa relação já no início, na carta de Natanael para Lothar:

Uma coisa horrível aconteceu comigo!
Pressentimentos inquietantes, terríveis,
ameaçadores, passam-me pela cabeça como
nuvens negras no temporal, impenetráveis aos
raios alegres da amizade. Você me pede que Ihe
conte o que me aconteceu. É necessário que eu
conte, bem sei, mas só de pensar nisso começo a
rir como um demente. (HOFFMANN, 2010, p.14)

Ainda que o riso da personagem hoffmanniana não seja exatamente aquela reação regeneradora da qual fala Bakhtin, o excerto é interessante para nossos propósitos uma vez que aproxima a coisa horrível que acometeu o protagonista a uma reação cômica. Em o Horror sobrenatural em literatura, ao tratar da obra de Hoffmann e de um grupo de narrativas de Allan Poe, Lovecraft observa justamente uma tendência à extravagância que contribuiria para a produção de efeitos grotescos (LOVECRAFT, 2007, p.53-65). Desse modo, ainda que não explore os desdobramentos cômicos das narrativas de horror, Lovecraft parece não ignorar as relações entre o horror e o humor, embora privilegie o primeiro em detrimento do segundo.

Bakhtin, por sua vez, assim como Lovecraft, aparenta compreender que o triunfo do riso no grotesco medieval não é o único desdobramento estético do medo cósmico. Suas considerações sobre o grotesco romântico, embora prejudicadas por seus juízos de valor, indicam a relação do grotesco não só com 
o humor, mas também com o horror. Assim, embora privilegiem aspectos distintos do mesmo fenômeno antropológico, Lovecraft e Bakhtin acabam por confirmar o quão tênues podem ser as fronteiras do medo e do riso.

\section{REFERÊNCIAS}

BAKHTIN, Mikhail (2010). A cultura popular na Idade Média e no Renascimento: o contexto de François Rabelais. 7ed. São Paulo: Hucitec.

BURKE, Edmund (1993). Uma investigação filosófica sobre a origem de nossas ideias do sublime e do belo. Campinas: Papirus.

CARROLL, Noël (1999). A filosofia do horror ou paradoxos do coração. Campinas: Papirus.

. (1999). "Horror and humor". In: The Journal of Aesthetics and Art Criticism, 57(2), p.145-160.

DOUGLAS, Mary (1991). Pureza e perigo; ensaio sobre as noções de Poluição e Tabu. Lisboa: Edições 70.

FRANÇA, Júlio (2010). "Fundamentos estéticos da literatura de horror: a influência de Edmund Burke em H. P. Lovecraft". In: Caderno Seminal Digital, 14(14), p.73-89.

. (2017). "A categoria estética do grotesco e as poéticas realista; uma leitura de 'Violação' de Rodolfo Teófilo". In: WERKEMA, Andréa; OLIVEIRA, Ana Lúcia; SOARES, Marcus Vinicius (Orgs.). Figurações do real: literatura brasileira em foco. Belo Horizonte, MG: Relicário Edições. p.219-235.

HOFFMANN, Ernst Theodor Amadeus (2010). O homem da areia. Rio de Janeiro: Rocco.

LOVECRAFT, Howard Phillips (2007). O horror sobrenatural em literatura. São Paulo: lluminuras. . (2012). O chamado de Cthulhu e outros contos. São Paulo: Hedra.

WALPOLE, Horace (1996). Prefácio à segunda edição. In: . O castelo de

Otranto. São Paulo: Nova Alexandria. p.19-27. 